Classification

Physics Abstracts

2.632

\title{
TOWARD A COMBUSTION-DRIVEN MIXING GDL
}

\author{
R. BAILLY, M. PÉALAT and J. P. E. TARAN \\ Office National d'Études et de Recherches Aérospatiales, \\ 92320 Châtillon, France
}

(Reçu le 23 mars 1977, accepté le 8 juillet 1977)

\begin{abstract}
Résumé. - Nous évaluons l'effet de divers polluants sur le laser thermique à mélange à $\mathrm{N}_{2} / \mathrm{CO}_{2} / \mathrm{He}$ de l'ONERA. L'intérêt a porté sur les composés susceptibles d'apparaître dans un système à combustion. Pour nos conditions de chambre $(12$ bars, $3000 \mathrm{~K})$, nous trouvons qu'un maximum de $5 \%$ de $\mathrm{H}_{2} \mathrm{O}, 10 \%$ de $\mathrm{H}_{2}$ ou $15 \%$ de $\mathrm{CO}_{2}$ en volume est tolérable. D'autre part, $\mathrm{CO}$ a un effet important sur le gain, par suite d'un mauvais couplage vibrationnel avec $\mathrm{CO}_{2}$. Si la proportion de $\mathrm{CO}$ est grande dans l'écoulement de $\mathrm{N}_{2}$, un meilleur effet laser est obtenu avec $\mathrm{N}_{2} \mathrm{O}$ qu'avec $\mathrm{CO}_{2}$ sur notre installation à petite échelle.
\end{abstract}

Abstract. - The influence of various pollutants on the ONERA $\mathrm{CO}_{2} / \mathrm{N}_{2} / \mathrm{He}$ mixing GDL is evaluated. Special attention is paid to those chemicals likely to appear in a combustion-driven system. For our plenum conditions $\left(12 \mathrm{~atm}, 3000 \mathrm{~K}\right.$ ), it is found that at most $5 \% \mathrm{H}_{2} \mathrm{O}, 10 \% \mathrm{H}_{2}$, or $15 \% \mathrm{CO}_{2}$ by volume can be tolerated among combustion products. It is also observed that $\mathrm{CO}$ has a large effect on gain due to lack of coupling to $\mathrm{CO}_{2}$. If the $\mathrm{CO}$ fraction is large, $\mathrm{N}_{2} \mathrm{O}$ proves superior to $\mathrm{CO}_{2}$ for laser action on the small-scale derice used

Several mixing $\mathrm{CO}_{2}$ lasers with thermal excitation have been operated in recent years [1-6]. Gains in excess of $4 \% \mathrm{~cm}^{-1}$ were observed, with laser efficiencies of $1.6 \%$ and specific powers of $25 \mathrm{~kW} / \mathrm{kg} / \mathrm{s}$ $[4,5]$. The success of mixing schemes is attributable to several advantages:

(i) the $\mathrm{N}_{2}$ plenum temperature can be raised to very high values without the penalty of large deactivation by $\mathrm{CO}_{2}$ and $\mathrm{H}_{2} \mathrm{O}$ or $\mathrm{He}$ during the expansion;

(ii) because the latter gases are injected cold into the main stream, the static temperature in the mixture downstream is lowered; a small expansion ratio nozzle thus can be used, in spite of the much higher stagnation temperatures;

(iii) a variety of other gas combinations can also be used.

There are, however, a number of difficulties:

(i) the mixing introduces aerodynamic disturbances and flow non-uniformity:

- in the downstream mixing schemes [1, 2], strong shocks are formed due to the different flow velocities; this problem may be cured in a screen nozzle arrangement by allowing the gradients to decay over a distance large compared to the nozzle size [6];

- in the throat mixing scheme [3-5], only weak shocks are formed and the gradients decay in a shorter distance; but the composition of the flow still varies somewhat from centerline to walls; some refinements can be devised in order to restore excellent uniformity [7];

(ii) axial injectors located on the flow centerline [3-5] are delicate to machine and may be damaged by long $\mathrm{cw}$ operation if not cooled properly;

(iii) there is at present no simple, efficient way of producing the hot $\mathrm{N}_{2}$ with large mass flow rates. Shock tubes $[3,6]$ and arc heaters $[4,5]$ have been used so far. Ideally, the system should be powered by a rocket-type burner operating at $2500 \mathrm{~K}$ or more. Unfortunately, most chemical reactions also release large mole fractions of $\mathrm{CO}_{2}, \mathrm{CO}, \mathrm{H}_{2} \mathrm{O}$, and particulate matter.

It is precisely the purpose of the present work to assess the influence of these pollutants on the efficiency, so that guidelines for the selection of appropriate fuel and oxidizer pairs can be established. Various gases thus have been mixed and sent into the arc heater and injector. Our efforts were concentrated on the influence of $\mathrm{CO}$, for which only limited results have so far been reported [6,8]. Gains were measured, and laser action was obtained from $\mathrm{CO}_{2}$ and $\mathrm{N}_{2} \mathrm{O}$ under different conditions. Some improvements were also made in the injector design.

1. Set-up. - The work reported herein was carried out with the set-up described in previous publi- 
cations $[4,5]$. The $2 \mathrm{MW}$ arc heater can provide a hot flow of gas at a maximum pressure of $12 \mathrm{~atm}$ and temperatures ranging from 2000 to $5000 \mathrm{~K}$ depending on mass flow rate and electrical power; $\mathrm{N}_{2}, \mathrm{CO}$, air, $\mathrm{H}_{2}$ or a combination of any two of these species, can be supplied at the selected mass flow rate through adequate feed lines. The stagnation temperature is adjusted by changing the discharge series resistor; it is best measured, with an accuracy of $\pm 200 \mathrm{~K}$, by calculating the difference between the electrical power dissipated in the discharge, and the heat carried away by the water cooling the arc assembly. Steady state is reached in 3 seconds, and the runs last usually 5 to 10 seconds altogether.

The nozzle and injector stage is unchanged from its original configuration (Fig. 1), except for the minor
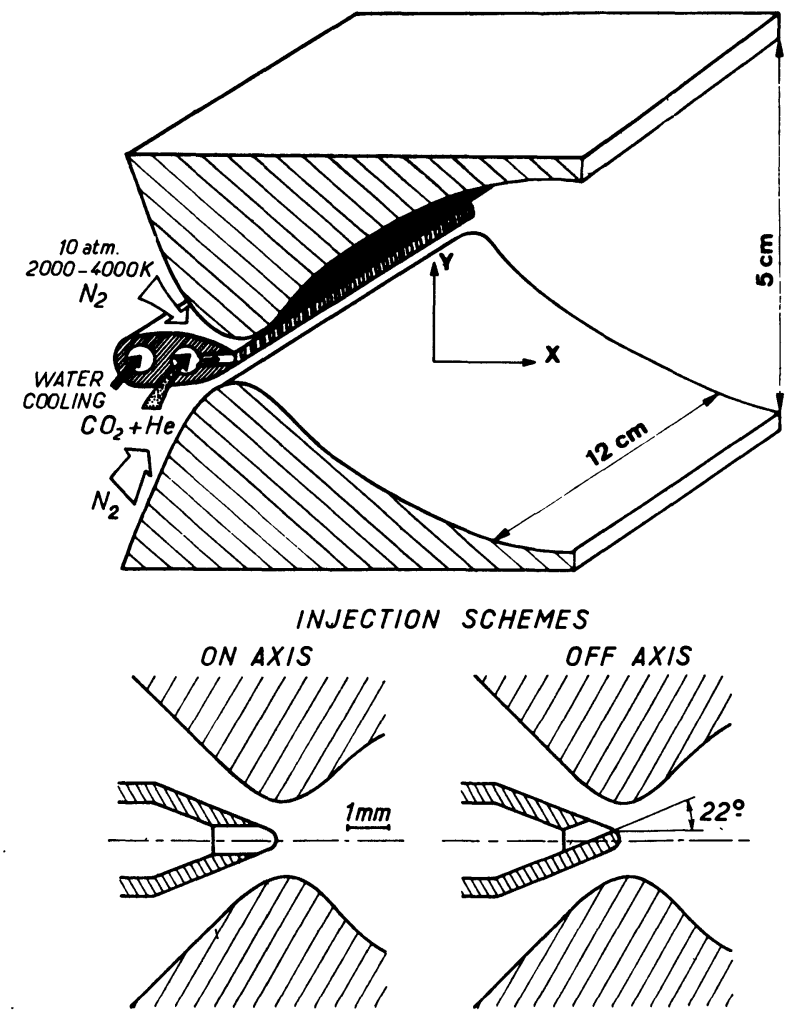

FIG. 1. - Sketch of the supersonic nominal Mach 5 nozzle arrangement and injection schemes studied.

injector change described in the next section, which resulted in an improved flow uniformity. Results obtained by injecting various proportions of $\mathrm{CO}_{2}$, $\mathrm{N}_{2} \mathrm{O}, \mathrm{He}$, and $\mathrm{H}_{2}$ will be reported below. Gains have been measured on several rotational lines of $\mathrm{CO}_{2}$, and oscillator experiments were performed with a 5-pass multimode cavity made of copper mirrors with a $6 \mathrm{~mm}$ thick $5 \mathrm{~cm} \times 5 \mathrm{~cm} \mathrm{ZnSe} \mathrm{etalon} \mathrm{as} \mathrm{the}$ output coupler. For this application the etalon is preferred over conventional reflectors because of its well-known transverse mode selecting properties and also because one does not have to use the expensive and fragile partially transmitting dielectric coa- tings. Due to the Fabry-Perot effect the reflective coefficient can reach $45 \%$ for the resonant cavity modes, although the coefficient at the $\mathrm{ZnSe} /$ air interface is only $17 \%$. Powers were measured with a homemade calorimeter of $0.2 \mathrm{~s}$ risetime coupled to differentiating electronics.

2. Injection and flow uniformity. - If energy is to be extracted efficiently, the flow of mixed gases should be as homogeneous and uniform as possible. In the experiments reported in references $[4,5]$, about $30 \%$ of the $\mathrm{N}_{2}$ stream near the nozzle walls was left with little or no $\mathrm{CO}_{2}$ injected, and therefore its vibrational energy could not be extracted efficiently. An improvement thus had to be made in our old injector design. This was done by using larger holes: the gases passing through the holes penetrate deeper into the main hot $\mathrm{N}_{2}$ stream, thus reaching closer to the nozzle walls; in addition, mixing is completed further downstream in a zone of lower temperature and density, which improves freezing efficiency and minimizes pollutant interference.

The improvement in flow uniformity is seen in figure 2, where 3 injector hole configurations are compared by means of the distribution of small signal gain they achieve about $15 \mathrm{~cm}$ downstream

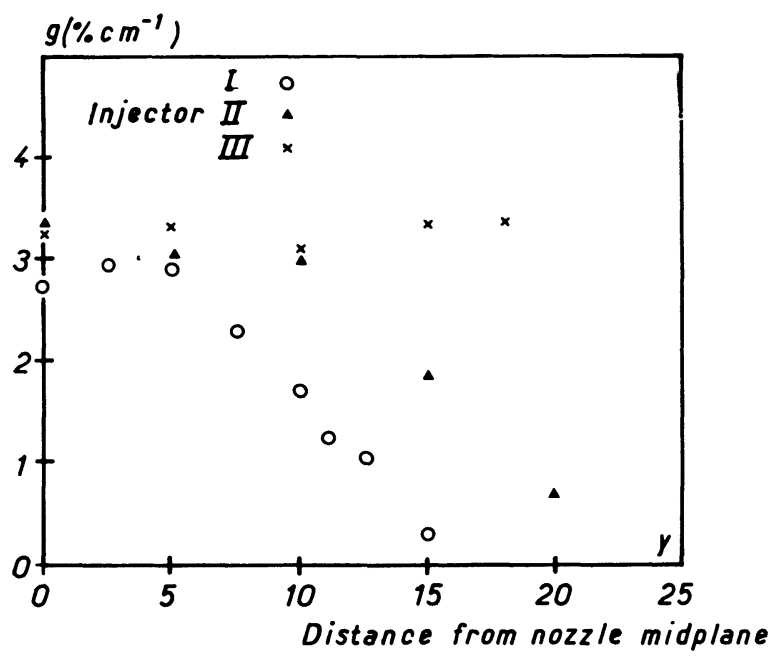

FIG. 2. - Gain distribution for three injector configurations. Injector I: $0.8 \mathrm{~mm}$ holes in the nozzle midplane, with $1.3 \mathrm{~mm}$ spacing; injector II: same size holes oriented $22^{\circ}$ to the midplane, alternately up and down; injector III: same as injector II, but holes are $1.2 \mathrm{~mm}$ in diameter and $2.4 \mathrm{~mm}$ apart.

from the throat. Note in passing that these distributions are not appreciably different $10 \mathrm{~cm}$ further downstream within measurement errors. Small signal gain is only one of the several parameters, like concentration; available laser energy, velocity or temperature, that could be used to probe the flow; it is, however, the easiest to measure. We also verified that the static temperature, as obtained from the gain distribution among the $\mathrm{P}(J)$ lines, does not increase by more than $30 \%$ from centerline to edges for the new injector. 
3. Influence of plenum gas composition. - The potential class of fuels for the combustion-driven GDL is limited. The ideal combustion should give a large fraction of $\mathrm{N}_{2}$ at temperatures in excess of $2500 \mathrm{~K}$, with minimal concentration of deactivating agents like $\mathrm{CO}_{2}$ and $\mathrm{H}_{2} \mathrm{O}$. The most attractive candidates are polymers or dehydrogenated organic adducts of the $\mathrm{C} \equiv \mathrm{N}$ radical, which are, however, toxic, unstable or difficult to prepare for the most part. The best oxidizer is $\mathrm{N}_{2} \mathrm{O}$; the equivalence ratio ideally should be 2 , so that only $\mathrm{N}_{2}$ and $\mathrm{CO}$ but no $\mathrm{CO}_{2}$ are formed, the $\mathrm{CO}$ possessing vibrational relaxation rates of the same order as $\mathrm{N}_{2}$. On the other hand, note that the requirements on fuel composition would be much relaxed if some $\mathrm{H}_{2} \mathrm{O}$ could be tolerated among the combustion products.

Therefore, we carried out a major effort to determine the influence of $\mathrm{CO}$ and $\mathrm{H}_{2} \mathrm{O}$ on freezing efficiency. Research on another pollutant, viz. $\mathrm{H}_{2} \mathrm{O}$, and another lasing molecule, viz. $\mathrm{N}_{2} \mathrm{O}$, was also carried out for the sake of completeness. One reservation must be expressed concerning the purity of the products after their heating by the arc. Significant decomposition may occur for some species like $\mathrm{O}_{2}$ or $\mathrm{H}_{2} \mathrm{O}$. In addition, partial reactions with the evaporated electrode material ( $\mathrm{Cu}$ vapour) and $\mathrm{SiO}_{2}$ from the porous walls through which the gases are fed are possible. Appreciable deposits of all these substances on the nozzle walls are observed after several minutes of operation. It does not seem, however, that they have a large effect on freezing efficiency when pure $\mathrm{N}_{2}$ is used.

4. CO. - The influence of $\mathrm{CO}$ on the gain as a function of temperature can be found in figure 3 . The net mass flow rate of the $\mathrm{N}_{2}+\mathrm{CO}$ mixtures was kept constant at $100 \mathrm{~g} / \mathrm{s}$ (3.6 moles/s). The injector was of type III and was fed with a fixed flow rate of $\mathrm{CO}_{2}+\mathrm{He}(1.46$ and $3.3 \mathrm{moles} / \mathrm{s}$, respectively). The gain on the $\mathrm{P}, 18$ line was measured on the flow centerline. These results establish the following points:

(i) For pure $\mathrm{N}_{2}$, the freezing efficiency is maintained from 2500 to $5000 \mathrm{~K}$ as seen from the comparison between the solid curve (shaped for a best fit to the data for all mixture compositions) and the dotted line which was obtained numerically taking a constant $80 \%$ figure $[4,5]$ for the net freezing efficiency (ie including $\mathrm{N}_{2}$ expansion and $\mathrm{CO}_{2}$ mixing). The levelling off at about $5000 \mathrm{~K}$ mostly reflects the influence of the growing partition function on the population of the 001 level of $\mathrm{CO}_{2}$. Croshko et al. [7] observed a larger drop beyond $3000 \mathrm{~K}$; this result is obtained if the static temperature in the expanded flow is growing faster, or if a line of lower $J$ is used for the gain measurement.

(ii) Similar trends are seen with $\mathrm{N}_{2}+\mathrm{CO}$ mixtures. The gain, however, is smaller, because the energy defect between $\mathrm{CO}_{2}$ and $\mathrm{CO}\left(224 \mathrm{~cm}^{-1}\right)$ is much larger than between $\mathrm{CO}_{2}$ and $\mathrm{N}_{2}\left(18 \mathrm{~cm}^{-1}\right)$. One can

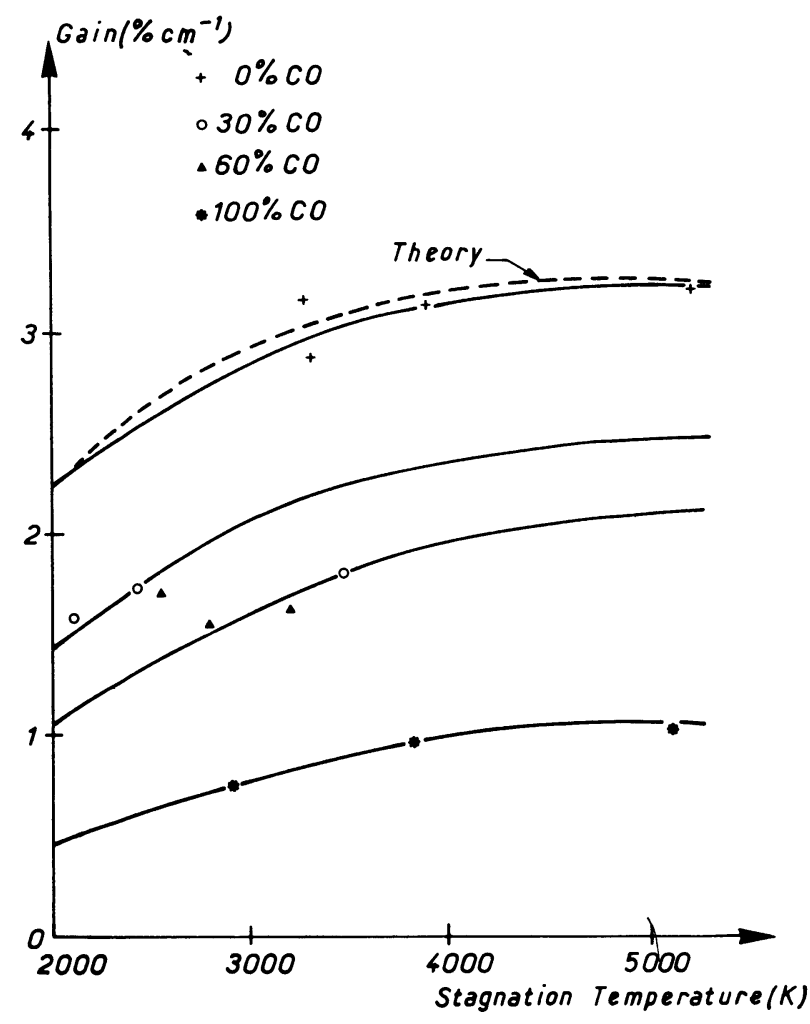

FIG. 3. - Gain vs plenum temperature for various $\mathrm{N}_{2} / \mathrm{CO}$ mixtures. The scatter in the data is larger for the 30 and $60 \% \mathrm{CO}$ cases because fewer runs were made; meanwhile the arc discharge appeared somewhat less stable.

calculate the gain drop resulting from the mismatch in vibration frequencies; to this end, we use a simple model [9] for two V-V coupled harmonic oscillators in a bath at temperature $T$ with no V-T relaxation, and arrive at:

$$
v_{1} / T_{1}-v_{2} / T_{2}=\left(v_{1}-v_{2}\right) / T .
$$

Here, $v_{1}$ and $v_{2}$ are the vibration frequencies of the oscillators, and $T_{1}$ and $T_{2}$ their respective vibrational temperatures. Using this equation and assuming all other parameters equal, we arrive at an approximate gain drop of $40 \%$ if we replace $\mathrm{N}_{2}$ by $\mathrm{CO}$, assuming $T=300 \mathrm{~K}$ and for a $4000 \mathrm{~K}$ stagnation temperature with $100 \%$ freezing efficiency. The gain is actually reduced by nearly $70 \%$, in satisfactory agreement with reference [8]. This result can be explained by the approximations in the vibrational model, by the fact that the rate constants for V-V transfer from $\mathrm{CO}$ are about 10 times smaller than for $\mathrm{N}_{2}$ at room temperature [10], and also by possible partial decomposition of $\mathrm{CO}$ in the arc.

These statements are corroborated by power extraction experiments (Fig. 4). A fixed arc heater mass flow rate of $70 \mathrm{~g} / \mathrm{s}$ was maintained, the $\mathrm{CO}$ mole fraction being varied. The $\mathrm{CO}_{2}$ and $\mathrm{He}$ were kept at 1.2 and $3 \mathrm{moles} / \mathrm{s}$, respectively. The stagnation temperature was held in the range $2500-3000 \mathrm{~K}$, and we estimate the static temperature in the flow at about $350 \mathrm{~K}$. The large drop in laser power with 


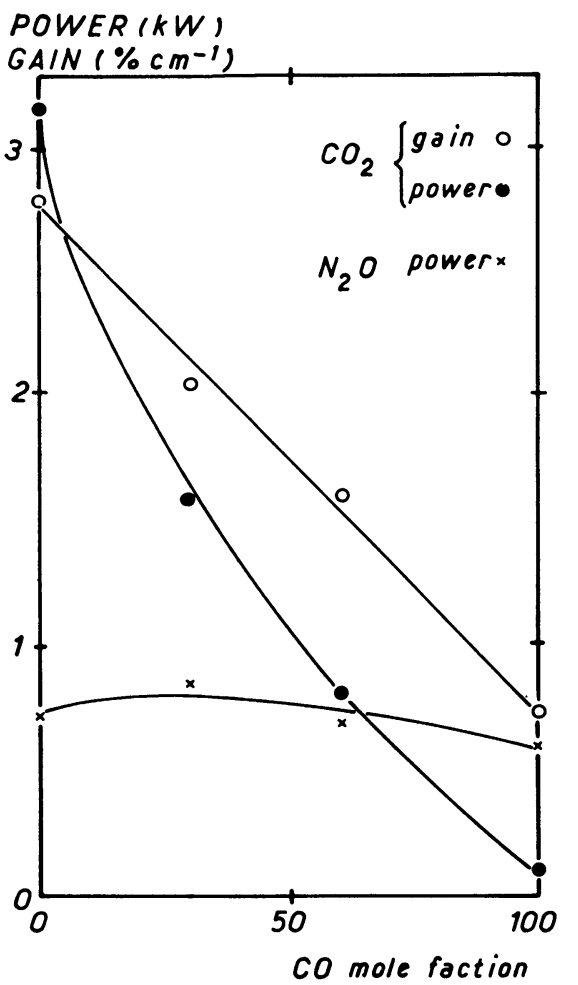

Fig. 4. - Power and gain results for $\mathrm{CO}_{2}$ and $\mathrm{N}_{2} \mathrm{O}$; the stagnation temperature is about $3000 \mathrm{~K}$.

increasing $\mathrm{CO}$ fraction results from the inability of the $\mathrm{CO}_{2}$ to extract the vibrational energy stored in the CO. This effect is enhanced by the degradation of laser cavity performance with low gain gas mixtures: the cavity threshold is reached for gains in excess of $0.75 \% \mathrm{~cm}^{-1}$ or thereabouts. The gain is also given for comparison, although it was obtained for $100 \mathrm{~g} / \mathrm{s}$ flow rate of $\mathrm{N}_{2}+\mathrm{CO}$. It is anticipated that a larger system (our single-pass gain-length is only $12 \mathrm{~cm}$ ) with a wider cavity in the flow direction would behave much better, even for the largest $\mathrm{CO}$ fractions.

In this respect, it is interesting to examine the results obtained by injecting $\mathrm{N}_{2} \mathrm{O}$ instead of $\mathrm{CO}_{2}$; the 001 level of $\mathrm{N}_{2} \mathrm{O}$ lies halfway between those of $\mathrm{N}_{2}\left(2331 \mathrm{~cm}^{-1}\right)$ and $\mathrm{CO}\left(2125 \mathrm{~cm}^{-1}\right)$, and fairly efficient coupling with these two molecules is possible. The results are also plotted in figure 4, although some conditions are somewhat different. In particular, the output reflector was a hole coupled copper mirror with $70 \%$ reflection, and the static temperature was lower (estimated $200 \mathrm{~K}$ ); the lower temperature was obtained with a different injector position at the throat; a flow rate of 1.8 moles/s of $\mathrm{N}_{2}$ was used. Although the power extracted is lower than for $\mathrm{CO}_{2}$ with pure $\mathrm{N}_{2}$, there is almost no dependence vs $\mathrm{CO}$ fraction. We believe that these power figures, which to our knowledge are the largest reported to date on a cw $\mathrm{N}_{2} \mathrm{O}$ laser, could reach the levels obtained with $\mathrm{CO}_{2}$. For that, however, it seems desirable to increase the gain length through the flow. Analogous results on comparison of performance were obtained by Stregack and coworkers [11] with their EDGDL, and the thorough analysis by Biryukov and coworkers tends to the same conclusions [12]. Finally, note that partial oxidation of $\mathrm{CO}$ by $\mathrm{N}_{2} \mathrm{O}$ in the mixing zone near the injector, where the static temperature is still high, may take place causing loss of gain and laser energy. This combustion is probably negligible with the conditions at which the $\mathrm{N}_{2} \mathrm{O}$ laser tests were conducted, but may partly explain why no laser effect was observed under the conditions realized for the $\mathrm{CO}_{2}$ tests.

5. Pollutants with minor concentrations. - Information has been gathered about $\mathrm{H}_{2} \mathrm{O}, \mathrm{O}_{2}, \mathrm{CO}_{2}$ and $\mathrm{H}_{2}$. Due to the difficulty of producing a homogeneous mixture of $\mathrm{H}_{2} \mathrm{O}$ vapour and $\mathrm{N}_{2}$ and of avoiding condensation along the lines, we preferred sending appropriate mixtures of air and $\mathrm{H}_{2}$ through the arc discharge, the $\mathrm{H}_{2}$ burning to produce $\mathrm{H}_{2} \mathrm{O}$.

Replacing $\mathrm{N}_{2}$ by an equal flow of air essentially showed that $\mathrm{O}_{2}$ can be treated as an inert gas, reducing gain in proportion to its mole fraction; a similar result has been reported previously [7]. Adding $\mathrm{H}_{2} \mathrm{O}$ caused further reduction in gain and power. The runs were conducted by first waiting for steady state to make a reference measurement, and then sending in $\mathrm{H}_{2}$ for the final measurement. The ratio of these two values is plotted against $\mathrm{H}_{2} \mathrm{O}$ fraction in figure 5 . Two sets of data are given: gain as measured on the centerline for injectors type II and III, and power for injector III. It is seen that the bigger holes have a favorable effect, as discussed above. Note that for

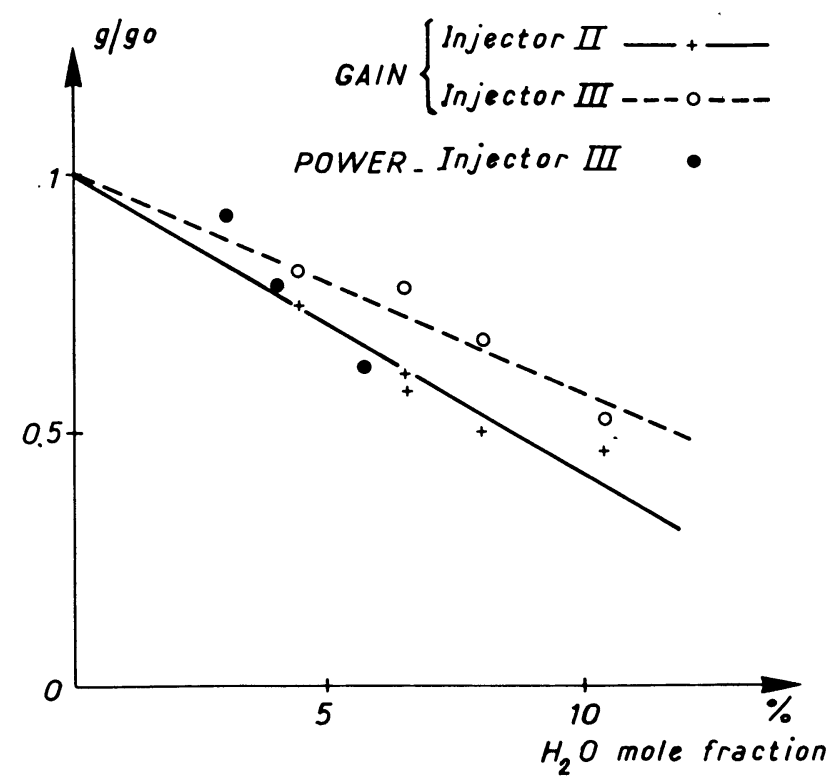

FIG. 5. - Relative gain drop $v s \mathrm{H}_{2} \mathrm{O}$ fraction; flow rates are: 2.15 moles $/ \mathrm{s}$ air, $1.46 \mathrm{moles} / \mathrm{s} \mathrm{CO}_{2}$ and $3.16 \mathrm{moles} / \mathrm{s} \mathrm{He}$.

these mixtures, the deactivation of $\mathrm{N}_{2}$ by $\mathrm{H}_{2} \mathrm{O}$ is due primarily to the $\mathrm{CO}_{2}$ which acts as a catalytic agent in the temperature range $300-1000 \mathrm{~K}$; this is inferred from the corresponding V-T rates [13]. 
The power, of course, drops faster since the optical cavity becomes less efficient as the gain is reduced. The main conclusion from those curves is that water still has an extremely deleterious effect, although its effect upon the laser efficiency is much less than on conventional GDL's. For atmospheric pressure recovery, the stagnation pressure must be raised to at least $50 \mathrm{~atm}$; then, a $2 \% \mathrm{H}_{2} \mathrm{O}$ mole fraction would cause about $50 \%$ loss in gain and available energy. In the absence of $\mathrm{H}_{2} \mathrm{O}$, the freezing efficiency is in the $80-100 \%$ range. If one is to keep the net freezing efficiency above $60 \%$ with the $\mathrm{H}_{2} \mathrm{O}$, then its mole fraction must not exceed $1 \%$. In addition, note that this result is given for pure $\mathrm{N}_{2}$ and not for $\mathrm{CO}+\mathrm{N}_{2}$ mixtures; $\mathrm{CO}$ is probably more sensitive to $\mathrm{H}_{2} \mathrm{O}$ deactivation [14] than $\mathrm{N}_{2}$.

The effect of $\mathrm{CO}_{2}$ is also interesting. For our tests, the $\mathrm{CO}_{2}$ was formed by addition of $\mathrm{CO}$ to the air sent through the arc heater. Due to the absence of $\mathrm{H}_{2} \mathrm{O}$, the deactivation appears appreciably reduced: typically, for an $8 \% \mathrm{CO}_{2}$ mole fraction, only $10 \%$ loss of available energy is observed.

The effect of $\mathrm{H}_{2}$ fraction in a pure heated $\mathrm{N}_{2}$ stream was briefly examined. An $11 \% \mathrm{H}_{2}$ fraction caused a $25 \%$ loss in available energy, which is in rough agreement with reference [6]. The result of injection at the throat was carefully studied. Judging from the rate constants in reference [13], $\mathrm{H}_{2}$ is a potential candidate for lower laser level deactivation; in addition, it has good heat conductivity and can also provide rapid cooling in the throat region. The gain $v s \mathrm{H}_{2}$ flow rate is presented on figure 6 . It is

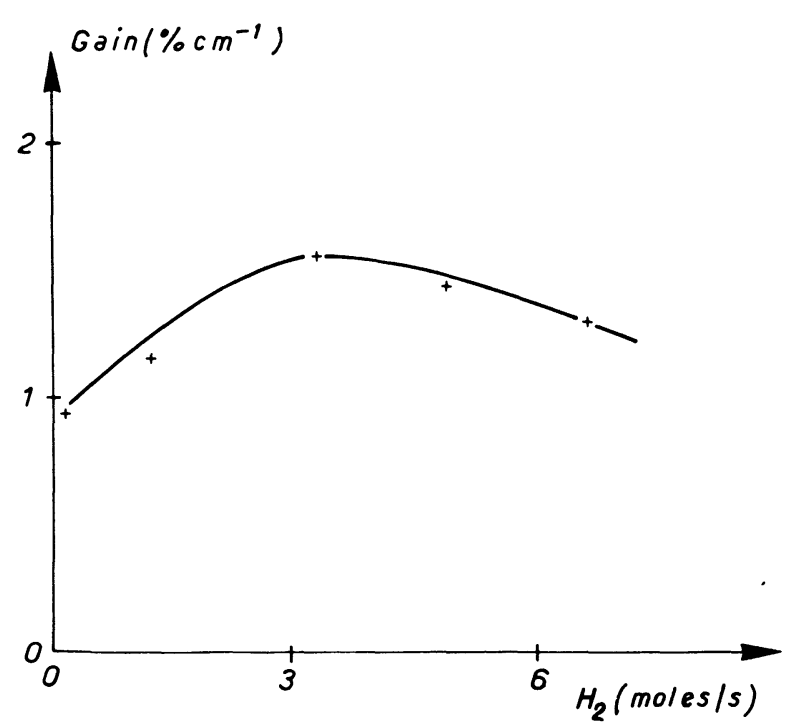

Fig. 6. - Effect of $\mathrm{H}_{2}$ injection at the throat on gain; flow rates for $\mathrm{N}_{2}$ and $\mathrm{CO}_{2}$ are 2 and $1.46 \mathrm{moles} / \mathrm{s}$ respectively.

clear that inversion is indeed achieved, even for the largest $\mathrm{H}_{2}$ mole fractions. Clearly also, $\mathrm{H}_{2}$ causes little deactivation if present in the downstream portion, since the gain does not drop appreciably for the largest flow rates (note that in the most extreme case, the $\mathrm{H}_{2}$ flow is nearly $2 / 3$ of the total flow). However, the gain remains small, i.e. less than half that obtained with equivalent mole flow rates of He. One may think of the following explanations: (i) the static temperatures are slightly larger than for He mixtures, as actually observed by probing various rotational lines; (ii) the $\mathrm{CO}_{2}$ lines experience large collisional broadening by $\mathrm{H}_{2}$. However, no laser action could be obtained with these mixtures, and we interpret this as indication that $\mathrm{H}_{2}$ is unable to deactivate the lower level properly.

6. Discussion. - This investigation has established some of the guidelines for the choice of the chemicals most suitable for the combustion-driven mixing GDL, and also has given a more precise idea of potential performance. The main advantages of this type of laser are:

(a) large gains and specific energies: some of the tests done with our system yielded gains in excess of $5 \% \mathrm{~cm}^{-1}$ (on the P12 line, for the conditions of figure 2 with injector III, but with a larger expansion ratio to give a static temperature of about $150 \mathrm{~K}$ ). The power exceeds $3 \mathrm{~kW}$ for pure $\mathrm{N}_{2}$ (Fig. 4), the specific power being $50 \mathrm{~kW}$ per $\mathrm{kg} / \mathrm{s}$ of $\mathrm{N}_{2}$. We estimate the power wasted because of mirror losses and incomplete saturation to be of the same order. In brief, and including the necessary mass flux of $\mathrm{CO}_{2}$ and $\mathrm{He}$ or $\mathrm{H}_{2} \mathrm{O}$, a large system, properly optimized, should be able to offer specific energies well in excess of $50 \mathrm{~kJ} / \mathrm{kg}$, i.e. in the same range as electrical lasers. Recently, three types of mixing arrangements were compared [15], namely injection through the nozzle sidewalls, injection through a central body as on our system, and a screen nozzle of the type developed by Cassady and coworkers [6]. This investigation concluded that the latter was superior, yielding $23 \mathrm{~kJ} / \mathrm{kg} \mathrm{N} \mathrm{N}_{2}$ on a very small device (35 mm active length). Such a comparison should also be made on a larger system, where cavity extraction efficiency depends less on optical gain, for a full evaluation to be made.

(b) The ability to choose the emitted wavelength: operation on transitions of $\mathrm{CO}_{2}$ and $\mathrm{N}_{2} \mathrm{O}$ molecules has been obtained. More molecules, like $\mathrm{CS}_{2}$ and $\mathrm{C}_{2} \mathrm{H}_{2}$, could be made to lase [11], but anticipated efficiencies are lower. Laser action on $\mathrm{CO}$ transitions has potential for larger efficiencies than $\mathrm{CO}_{2}$, but the drawback is that static temperatures below $150 \mathrm{~K}$ must be obtained. We failed to observe CO laser action using hot $\mathrm{N}_{2} / \mathrm{CO}$ mixtures and injecting argon. Insufficiently low static flow temperatures, insufficient gain length and large mirror losses are blamed for this negative result.

The effect of some pollutants was assessed. Extremely deleterious effects are seen with $\mathrm{H}_{2} \mathrm{O}$ and $\mathrm{H}_{2}$, the permissible levels being on the order of $1 \%$ for $\mathrm{H}_{2} \mathrm{O}$, and $2 \%$ for $\mathrm{H}_{2}$ if the stagnation pressure is to be raised to about $50 \mathrm{~atm}$. Several percent $\mathrm{CO}_{2}$ 
are acceptable; this is essential for a combustion driven system, since one wants to achieve high equivalence ratios, as near 2 as possible, but still not have the production of soot which is unavoidable in the vicinity of 2 . Strictly speaking, $\mathrm{CO}$ cannot be labelled as a pollutant. The available laser energy in the flow is hardly affected by its presence; however, the $\mathrm{CO}_{2}$ molecule has difficulty in extracting the vibrational energy stored in the levels of $\mathrm{CO}$ due to the energy defect. Whether the situation improves much on a larger scale device is still an open question. If not, then $\mathrm{N}_{2} \mathrm{O}$ will be an extremely attractive substitute for $\mathrm{CO}_{2}$ for laser action.

Optical homogeneity has not been determined quantitatively. This will be best done on a system more representative of a large scale laser, i.e. with an array of parallel nozzles offering an optical path of $30 \mathrm{~cm}$ or more. A qualitative schlieren study of the present system, in a direction parallel to the throat, had shown [5] that small scale turbulence was of the same order as that of a conventional GDL flow without injector. We must point out that since the working medium offers more gain and energy, the optical path is reduced for a given output power; this relaxes the requirements on optical quality.

Finally, the production, by combustion, of hot $\mathrm{N}_{2}$ with an admixture of other acceptable reaction products has yet to be demonstrated. Temperatures of at least $2500 \mathrm{~K}$ and optimally $3000 \mathrm{~K}$ are needed for the laser to be efficient. This restricts the choice of possible fuels considerably. An exhaustive investigation of GDL fuels had been completed by Pallay and Zovko [16]. Few of these fuels appear fully satisfactory for a mixing GDL, either because of excess pollutant formation or because of insufficient combustion enthalpy. The only technically acceptable choice is $\mathrm{C}_{2} \mathrm{~N}_{2}$, which is toxic; preheating may also offer a wider choice of acceptable chemicals. The future of mixing GDL's depends on developments in these areas.

\section{References}

[1] Bronfin B. R., Boedeker L. R. and Cheyer J. P., Appl. Phys. Lett. 16 (1970) 214.

[2] Milewski J., Brunné M., Stanco J., Zielinski A., IrCzuk M. and Kusmierek J., Bull. Acad. Pol. Sci. Sér. Sci. Tech. 20 (1972) 73.

[3] Croshro V. N., Soloukhin R. I. and Wolanski P., Opt. Commun. 6 (1972) 275; also in: Proceedings of the 9th International Shock Tube Symposium, Eds. Bershader, D. and Griffith, W., (Stanford Univ. Press) 1973, 167.

[4] Borghi R., Carrega A. F., Charpenel M. and J.P.E. Taran, Appl. Phys. Lett. 22 (1973) 661.

[5] Taran J.P.E., Charpenel M. and Borghi R., AIAA Paper No. 73-622, presented at the AIAA 6th Fluid and Plasma Dynamics Conference, Palm Springs, California (1973).

[6] Cassady P. E., Newton J., Rose P., AiAA Paper No. 76-343, presented at the AIAA 9th Fluid and Plasma Dynamics Conference, San Diego, California (1976).

[7] Croshro V. N., Fomin N. A. and Soloukhin R. I., Acta Astronautica 2 (1975) 929.
[8] Tennant R., Vargas R. and Hadley S., AiAA Paper No. 74178 , presented at the AIAA $12^{\text {th }}$ Aerospace Sciences Meeting, Washington, D.C. (1974).

[9] Basov N. G., Mickhailov V. G., Oraevski A. N. and ShCheGLov V. A., Sov. Phys. Tech. Phys. 13 (1969) 1630.

[10] Gueguen H., Arditi I., Margottin Maclou M., DoyennetTe L. and Henry L., C. R. Hebd. Séan. Acad. Sci. 272 (1971) 1139.

[11] Stregack J. A., Wexler B. L. and Hart G. A., Appl. Phys. Lett. 28 (1976) 137.

[12] Biryukov A. S., Volkov A. Yu., Demin A. I., KudryavtSev E. M., Kulagin Yu. A., Sobolev N. M. and ShelePIN L. A., Sov. Phys. JETP 41 (1976) 834.

[13] Taylor R. L. and Bitterman S., Rev. Mod. Phys. 41 (1969) 26.

[14] Matthews D. L., J. Chem. Phys. 34 (1961) 639.

[15] Shall W., Hoffman P. and Hügel H., J. Appl. Phys. 48 (1977) 688

[16] Pallay B. G. and Zovko C. T., AiAA Paper No. 73-1233, presented at the AIAA/SAE 9th Propulsion Conference, Las Vegas, Nevada (1973). 